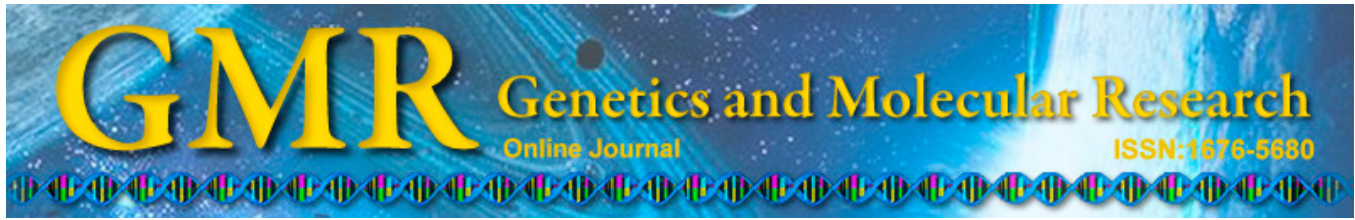

\title{
Association between rs155971 in the PCSK1 gene and the lipid profile of obese Thai children: a family-based study
}

S. Kulanuwat ${ }^{1}$, J. Santiprabhob ${ }^{2}$, B. Phonrat ${ }^{3}$, C. Limwongse ${ }^{4}$,

A. Tungtrongchitr ${ }^{5}$, N. Chongviriyaphan ${ }^{6}$ and R. Tungtrongchitr ${ }^{1}$

${ }^{1}$ Department of Tropical Nutrition \& Food Science, Faculty of Tropical Medicine, Mahidol University, Bangkok, Thailand

${ }^{2}$ Division of Endocrinology \& Metabolism, Department of Pediatrics, Faculty of Medicine Siriraj Hospital, Mahidol University, Bangkok, Thailand ${ }^{3}$ Department of Clinical Tropical Medicine, Faculty of Tropical Medicine, Mahidol University, Bangkok, Thailand

${ }^{4}$ Division of Molecular Genetics, Department of Research \& Development, Faculty of Medicine Siriraj Hospital, Mahidol University, Bangkok, Thailand ${ }^{5}$ Department of Parasitology, Faculty of Medicine Siriraj Hospital,

Mahidol University, Bangkok, Thailand

${ }^{6}$ Department of Pediatrics, Faculty of Medicine Ramathibodi Hospital, Mahidol University, Bangkok, Thailand

Corresponding author: R. Tungtrongchitr

E-mail: rungsunn.tun@mahidol.ac.th

Genet. Mol. Res. 14 (3): 9136-9144 (2015)

Received December 13, 2014

Accepted April 7, 2015

Published August 7, 2015

DOI http://dx.doi.org/10.4238/2015.August.7.23

ABSTRACT. Genetic variants of the POMC and PCSK1 genes cause severe obesity among patients in the early stages of childhood. This family-based study analyzed the links between single nucleotide polymorphisms (SNPs) in either the POMC or PCSK1 genes and obesity, as well as obesity-related traits among obese Thai children and their families. The variants rs1042571 and rs6713532 in the POMC gene in a sample of 83 obese children and their family members were investigated using polymerase chain reaction (PCR)-restriction 
fragment length polymorphism. In addition, the SNPs rs6232, rs155971, rs3762986, rs3811942, and rs371897784 of PCSK1 were analyzed in all samples using PCR and gene sequencing methods. Participants with the homozygous variant genotype in rs 155971 had significantly elevated cholesterol and low-density lipoprotein cholesterol (LDL-C) levels $(\mathrm{P}=0.011, \mathrm{OR}=1.025,95 \% \mathrm{CI}=1.006-1.045$; and $\mathrm{P}=0.006$, $\mathrm{OR}=1.030,95 \% \mathrm{CI}=1.009-1.053$, respectively) after adjustment for age, gender, and body mass index (BMI). In addition, patients with the heterozygous variant genotype in rs371897784 of PCSK1 had a 1.249fold higher risk $(95 \% \mathrm{CI}=1.081-1.444, \mathrm{P}=0.027)$ of increased waist circumference than patients with the normal genotype, after adjustment for age, gender, and BMI. However, this analysis did not find any correlation between obesity and SNPs in PCSK1 and POMC. Therefore, these common variants in PCSK1 and POMC were not the major cause of obesity in the Thai subjects sampled. However, variants in PCSK1 did affect cholesterol level, LDL-C level, and waist circumference.

Key words: $P O M C$ gene; $P C S K 1$ gene; Genetic variant; Obesity; Body mass index; Single nucleotide polymorphism

\section{INTRODUCTION}

The proopiomelanocortin gene (POMC), which has the chromosomal locus 2p23.3, is associated with obesity (Hager et al., 1998) and metabolic syndrome (Loos et al., 2003). The POMC protein is the main substrate of prohormone convertase $1 / 3(\mathrm{PC} 1 / 3)$, which controls the appetite. POMC is cleaved by PC1/3 to give the product $\alpha$-melanocyte-stimulating hormone, which binds to the melanocortin-4 receptor in the hypothalamus to control metabolism. The common variant C8246T (rs1042571), located in the 3'-untranslated region (UTR), was associated with waist-to-hip ratio (WHR) $(\mathrm{P}<0.0001)$ in a family study on a white British population (Baker et al., 2005). Moreover, in the UK, this single nucleotide polymorphism (SNP) was associated with body mass index $(\mathrm{BMI})(\mathrm{P}=0.032)$ and total fat $(\mathrm{P}=0.046)$ in a recessive model (Chen et al., 2005). In Caucasian Americans, Wang et al. (2012) found an association between the $C 8246 \mathrm{~T}$ variant and $\mathrm{BMI}$ (overweight: $\mathrm{P}=0.005$; obese: $\mathrm{P}=0.018$; overweight + obese: $\mathrm{P}=0.002$ ) but not among African Americans. Another SNP in the intron of the POMC gene, rs6713532, was associated with WHR, visceral fat, and abdominal fat $(\mathrm{P}=0.020,0.019$, and 0.021, respectively) in a European population (Ternouth et al., 2011).

Another gene, the proprotein convertase subtilisin/kexin type 1 (PCSK1) gene, which has the chromosomal locus $5 \mathrm{q} 15-21$, encodes $\mathrm{PC} 1 / 3$. PC1/3 is a protein that converts a variety of prohormones and neuropeptide precursors, such as proinsulin and POMC, to their functional forms (Seidah et al., 1991; Pickett et al., 2013). One of the functions of PC1/3 is to control energy balance (Choquet and Meyre, 2010; Chung, 2012). Therefore, a variant in the PCSK1 gene can cause energy imbalance and obesity.

SNPs in PCSK1 have been found to cause early-onset obesity and diabetes-related traits in humans (Jackson et al., 1997, 2003; Farooqi et al., 2007; Benzinou et al., 2008; Heni et al., 2010). Many researchers have studied rs6232, the variant which has a guanine instead of an adenine in exon 6, thus resulting in the substitution of asparagines for aspartic acid (N221D) in the 
catalytic domain of $\mathrm{PC} 1 / 3$. This mutation decreases the activity of PC1/3 (Benzinou et al., 2008). The EPIC-Norfolk study in the UK found an association between rs6232 and obesity and BMI in younger individuals (age $<59$ years) but not among older subjects (Kilpeläinen et al., 2009). In a study of Mexican populations, it was found that rs6232 was significantly associated with childhood obesity and adult class III obesity [odds ratio $(\mathrm{OR})=3.01,95 \%$ confidence interval $(95 \% \mathrm{CI})=1.64-5.53]$ (Villalobos-Comparán et al., 2012). Other variants have been shown to have an association with obesity. The rs 155971 variant in intron 6 showed an association with obesity $(\mathrm{P}=0.01)$ in a Chinese population (Chang et al., 2010). In French Caucasians, rs 3762986 (5'-end gene) was significantly associated with an increased risk of obesity $(\mathrm{OR}=1.19,95 \% \mathrm{CI}$ $=1.06-1.34)$, whereas rs $3811942\left(3^{\prime}-\mathrm{UTR}\right)$ protected against obesity $(\mathrm{OR}=0.82,95 \% \mathrm{CI}=0.76$ 0.99) (Benzinou et al., 2008).

In Thailand, our previous research found an association between PCSK1 variants and obesity, which involved rs6234, rs6235, and rs3811951 (Kulanuwat et al., 2014). Several studies have investigated SNPs in POMC and PCSK1 genes, and the potential association with obesity, using anthropometric and biochemical parameters. The present study investigated members of obese Thai families to determine whether variations in the POMC and PCSK1 genes are associated with obesity-related traits.

\section{MATERIAL AND METHODS}

\section{Study subjects}

The study subjects were recruited from obese children and young adults aged 8-20 years at the Pediatric Outpatient Departments of Siriraj and Ramathibodi hospitals. Detailed descriptions of the study were published in our previous research (Kulanuwat et al., 2014). Briefly, POMC and PCSK1 SNPs were investigated in 83 samples from 12 families comprising 64 obese subjects and 19 non-obese subjects.

The obesity status of the adults was categorized by using the BMI for Asian populations (WHO/IASO/IOTF, 2000; Kagawa et al., 2006; Thaikruea et al., 2006); persons with $\mathrm{BMI} \geq 25 \mathrm{~kg} / \mathrm{m}^{2}$ were categorized as obese. For children, percent weight for height was used to classify overweight status and obesity by National Growth References for children aged $<20$ years from the Ministry of Public Health, Thailand and WHO (Waterlow et al., 1977). Children whose percent weight for height was $\geq 120$ were categorized as obese.

\section{Anthropometric measurements}

The waist circumference, body weight, and height of each individual were measured, and BMI was calculated. Percentage total body fat was measured by bioelectrical impedance analysis. The instrument used and the details of all the measurements have been described in our previous report (Kulanuwat et al., 2014).

\section{Laboratory measurements}

All samples were investigated for cholesterol, low-density lipoprotein cholesterol (LDL-C), high-density lipoprotein cholesterol, triglycerides, fasting blood glucose, insulin, and hemoglobin A1C (HbA1C) in the laboratory of Siriraj Hospital (Kulanuwat et al., 2014). 


\section{Polymerase chain reaction (PCR) amplification and genotyping}

Two variations of the $P O M C$ gene were analyzed using the PCR-restriction fragment length polymorphism (RFLP) method. The PCSK1 gene, composed of 5 SNPs, was investigated by PCR and DNA sequencing. All PCR primers were designed using the Primer3Plus program (Table 1).

Table 1. Primer sequences of $P C S K 1$ and $P O M C$ gene variants.

\begin{tabular}{lllc}
\hline Genetic variants & Forward primer $\left(5^{\prime} \rightarrow 3^{\prime}\right)$ & Reverse primer $\left(5^{\prime} \rightarrow 3^{\prime}\right)$ & Product size $(\mathrm{bp})$ \\
\hline rs6232 & TTGTGCCCTTCATCTGAACA & TGTAGCAACTTTGGCATGGA & 395 \\
rs155971 & TATATGCAGCCACCAATCCA & AAAATGAAGGGAGAAGCACAAA & 540 \\
rs3762986 & GAATGGGCTCCGATTGATAG & TCTGGCAAAGAGGTTCATAGG & 489 \\
rs3811942 & AGGAATGAGTGGCACTTTGG & TTCCTTACCCTGCGATTTTG & 498 \\
rs371897784 & TGTGAAATCCTTCCCAGAGG & ATGGATTCTGGGGAAAAACC & 482 \\
rs1042571 $($ C8246T) & TTCAAAAACGCCATCATCAA & ATGGAAACCACTGTGCTCCT & 306 \\
rs6713532 & CACCTGCTTTCTTGGCACTC & AACAACTACCACCCGTCTGC & 226 \\
\hline
\end{tabular}

For PCR-RFLP, the PCR products from rs 1042571 were incubated at $37^{\circ} \mathrm{C}$ for $2 \mathrm{~h}$ using restriction enzyme MboII (Baker et al., 2005). In addition, the PCR products from rs6713532 were incubated at $65^{\circ} \mathrm{C}$ for $3 \mathrm{~h}$ using restriction enzyme TspRI (Ternouth et al., 2011).

For DNA sequencing, the PCR products were purified to remove excess primer and primer dimers. The purified PCR products were then sent to Macrogen Inc., Seoul, South Korea, for sequencing using an Automatic Sequencer 3730X.

\section{Statistical analysis}

The Hardy-Weinberg equilibrium test was used to test all polymorphisms. Chi-square analysis was used to analyze the association between polymorphisms of the POMC and PCSK1 genes in the obese and control subjects. The Mann-Whitney U-test was used to test the difference for obesity-related parameters between wild-type and variant groups in all SNPs. The Kruskal-Wallis H-test was used to test the differences in biochemical and anthropometric parameters, among the wild-type, heterozygous variant, and homozygous variant genotypes. Logistic regression models were used to determine ORs and 95\%CIs, with data adjustment for age, gender, and BMI. The dependent variables of logistic regression analysis were genotypes of each SNP. All tests were performed using SPSS computer program version 16.0; a statistically significant association or difference was set at $\mathrm{P}<0.05$.

\section{Ethical considerations}

The study was approved by the Ethics Committee of the Faculty of Tropical Medicine, Mahidol University. All probands and their family members provided written informed consent.

\section{RESULTS}

This study analyzed seven SNPs, comprising two SNPs in the POMC gene and five in the PCSK1 gene. The genotype frequencies and minor allele frequencies of the six SNPs (exclud- 
ing rs6232) are shown in Table 2. Two SNPs - rs371897784 in the PCSK1 gene and rs1042571 in the POMC gene - did not have homozygous variant genotypes. For SNP rs6232, all 11 proband samples (children with $\geq 140 \%$ weight for height) were sequenced first; however, the results did not reveal any variant genotype, so this SNP was not investigated among their family members.

\begin{tabular}{|c|c|c|c|c|c|c|}
\hline Gene & SNP & Genotype & Frequency & Percent & Minor allele frequency & Hardy-Weinberg equilibrium ( $\mathrm{P}$ value) \\
\hline \multirow[t]{6}{*}{ POMC } & rs1042571 & $\mathrm{CC}$ & 68 & 81.9 & \multirow[t]{3}{*}{$\mathrm{T}=9.0 \%$} & \multirow[t]{3}{*}{0.365} \\
\hline & $(\mathrm{C}>\mathrm{T})$ & CT & 15 & 18.1 & & \\
\hline & & TT & 0 & 0 & & \\
\hline & rs6713532 & $\mathrm{CC}$ & 36 & 91.6 & \multirow[t]{3}{*}{$\mathrm{T}=31.3 \%$} & \multirow[t]{3}{*}{0.109} \\
\hline & $(\mathrm{C}>\mathrm{T})$ & CT & 42 & 8.4 & & \\
\hline & & TT & 5 & 0 & & \\
\hline \multirow[t]{12}{*}{ PCSK1 } & rs155971 & $\mathrm{CC}$ & 25 & 30.1 & \multirow{3}{*}{$\mathrm{T}=48.8 \%$} & \multirow[t]{3}{*}{0.154} \\
\hline & $(\mathrm{C}>\mathrm{T})$ & $\mathrm{CT}$ & 35 & 42.2 & & \\
\hline & & TT & 23 & 27.7 & & \\
\hline & rs 3762986 & $\mathrm{CC}$ & 29 & 34.9 & \multirow[t]{3}{*}{$\mathrm{T}=42.8 \%$} & \multirow[t]{3}{*}{0.415} \\
\hline & $(\mathrm{C}>\mathrm{T})$ & СТ & 37 & 44.6 & & \\
\hline & & TT & 17 & 20.5 & & \\
\hline & rs3811942 & AA & 66 & 79.5 & \multirow[t]{3}{*}{$\mathrm{G}=10.8 \%$} & \multirow[t]{3}{*}{0.978} \\
\hline & $(A>G)$ & AG & 16 & 19.3 & & \\
\hline & & GG & 1 & 1.2 & & \\
\hline & rs371897784 & GG & 72 & 86.7 & \multirow[t]{3}{*}{$\mathrm{A}=6.0 \%$} & \multirow[t]{3}{*}{0.517} \\
\hline & $(\mathrm{G}>\mathrm{A})$ & GA & 11 & 13.9 & & \\
\hline & & AA & 0 & 0 & & \\
\hline
\end{tabular}

For the association analyses of each SNP with anthropometric and biochemical parameters, the results revealed that rs 155971 of the PCSK1 gene had significantly different medians for cholesterol and LDL-C among the three genotypes $(\mathrm{P}=0.030$ and $\mathrm{P}=0.032$, respectively). After adjustment for age, gender, and BMI, there was a significant difference only between CC (wild-type genotype) and TT (homozygous variant genotype). A patient with the TT genotype had 1.025 greater risk of higher cholesterol level $(\mathrm{P}=0.011,95 \% \mathrm{CI}=1.006-1.045)$ and 1.030 greater risk of higher LDL-C level $(\mathrm{P}=0.006,95 \% \mathrm{CI}=1.009-1.053)$ than a patient with the $\mathrm{CC}$ genotype (Table 3$)$.

Table 3. Analysis of PCSK1 rs 155971 with anthropometric and biochemical parameters.

\begin{tabular}{lccccc}
\hline rs155971 $(\mathrm{C}>\mathrm{T})$ & $\mathrm{CC}(\mathrm{N}=25)$ & $\mathrm{CT}(\mathrm{N}=35)$ & $\mathrm{TT}(\mathrm{N}=23)$ & P value & Adjusted P value \\
\hline BMI & $28.3(25.6-38.4)$ & $28.4(24.3-33.8)$ & $30.9(26.0-36.0)$ & 0.619 & - \\
Waist circumference $(\mathrm{cm})$ & $96.0(81.0-111.3)$ & $95.0(84.5-103.0)$ & $94.3(89.0-111.4)$ & 0.862 & - \\
Total body fat percentage & $32.0(27.5-38.1)$ & $35.0(27.3-37.8)$ & $36.2(29.4-39.0)$ & 0.493 & - \\
Cholesterol $(\mathrm{mg} / \mathrm{dL})$ & $186.0(169.0-199.5)$ & $196.0(175.0-222.0)$ & $210.0(182.0-231.0)$ & 0.030 & $0.171^{\mathrm{a}}, 0.011^{\mathrm{b}}(\mathrm{OR}=1.025$, \\
& & & & $95 \% \mathrm{CI}=1.006-1.045)^{\mathrm{b}}$ \\
Triglyceride $(\mathrm{mg} / \mathrm{dL})$ & $117.0(93.5-150.5)$ & $117.0(65.0-166.0)$ & $99.0(83.0-141.0)$ & 0.648 & - \\
LDL-C $(\mathrm{mg} / \mathrm{dL})$ & $114.6(90.3-125.1)$ & $118.4(101.2-133.4)$ & $147.4(105.4-155.6)$ & 0.032 & $0.101^{\mathrm{a}}, 0.006^{\mathrm{b}}(\mathrm{OR}=1.030$, \\
& & & & $95 \% \mathrm{CI}=1.009-1.053)^{\mathrm{b}}$ \\
HDL-C $(\mathrm{mg} / \mathrm{dL})$ & $49.0(40.5-63.0)$ & $50.0(44.0-61.0)$ & $55.0(46.0-61.0)$ & 0.798 & - \\
Glucose $(\mathrm{mg} / \mathrm{dL})$ & $90.0(87.0-101.0)$ & $92.0(86.0-97.0)$ & $91.0(84.0-115.0)$ & 0.992 & - \\
HbA1C $(\%)$ & $5.9(5.6-6.4)$ & $5.9(5.5-6.3)$ & $6.0(5.6-6.8)$ & 0.817 & - \\
Insulin $(\mu \mathrm{U} / \mathrm{mL})$ & $13.3(10.7-28.7)$ & $10.3(6.1-17.5)$ & $10.3(8.3-20.6)$ & 0.179 & - \\
HOMA-IR & $3.63(2.30-9.21)$ & $2.42(1.39-3.93)$ & $2.74(1.92-6.52)$ & 0.237 & - \\
\hline
\end{tabular}

Data are reported as medians (interquartile range). $\mathrm{BMI}=$ body mass index; HOMA-IR $=$ homeostasis model assessment of insulin resistance; LDL-C = low-density lipoprotein cholesterol; HDL-C = high-density lipoprotein cholesterol. P value was compared among 3 genotypes by Kruskal-Wallis $\mathrm{H}$-test. ${ }^{a} \mathrm{P}$ value between $\mathrm{CC}$ and $\mathrm{CT}$ genotype, adjusted for age, gender, and BMI by multinomial logistic regression. ${ }^{\mathrm{P}} \mathrm{P}$ value and $\mathrm{OR}$ between $\mathrm{CC}$ and TT genotype, adjusted for age, gender, and BMI by multinomial logistic regression, where $\mathrm{CC}$ genotype was the reference group. 
The study found significant differences in median glucose and $\mathrm{HbA1C}$ levels among the three genotypes $(\mathrm{P}=0.015$ and $\mathrm{P}=0.009$, respectively $)$ of rs 3762986 in the PCSK1 gene; however, when adjusted for age, gender, and BMI, the differences were not statistically significant (Table 4).

\begin{tabular}{|c|c|c|c|c|c|}
\hline rs3762986 $(\mathrm{C}>\mathrm{T})$ & $\mathrm{CC}(\mathrm{N}=29)$ & $\mathrm{CT}(\mathrm{N}=37)$ & $\mathrm{TT}(\mathrm{N}=17)$ & $P$ value & Adjusted P value \\
\hline BMI & $28.0(24.5-36.9)$ & $28.8(24.9-34.8)$ & $31.7(27.4-37.6)$ & 0.262 & - \\
\hline Waist circumference $(\mathrm{cm})$ & $92.0(81.3-108.3)$ & $94.0(81.5-109.3)$ & $96.9(89.0-109.5)$ & 0.424 & - \\
\hline Total body fat percentage & $32.8(30.0-36.5)$ & $35.3(27.3-38.9)$ & $37.1(29.6-39.0)$ & 0.529 & - \\
\hline Cholesterol (mg/dL) & $188.0(169.0-212.5)$ & $206.0(187.0-226.0)$ & $197.0(177.0-208.5)$ & 0.136 & - \\
\hline Triglyceride (mg/dL) & $109.0(63.0-147.0)$ & $111.0(83.5-159.5)$ & $117.0(90.5-150.5)$ & 0.497 & - \\
\hline LDL Calculated (mg/dL) & $108.0(91.3-133.3)$ & $122.0(108.0-149.8)$ & $118.4(92.2-138.8)$ & 0.205 & - \\
\hline HDL-C (mg/dL) & $55.0(43.5-62.0)$ & $54.0(46.0-63.5)$ & $50.0(38.0-60.5)$ & 0.383 & - \\
\hline Glucose (mg/dL) & $91.0(87.0-97.5)$ & $88.0(84.0-100.5)$ & $97.0(91.5-127.5)$ & 0.015 & $>0.050^{\mathrm{a}, \mathrm{b}}$ \\
\hline $\operatorname{HbA} 1 \mathrm{C}(\%)$ & $5.7(5.4-6.2)$ & $5.9(5.6-6.2)$ & $6.8(5.9-7.8)$ & 0.009 & $>0.050^{\mathrm{a}, \mathrm{b}}$ \\
\hline Insulin $(\mu \mathrm{U} / \mathrm{mL})$ & $12.6(7.3-23.7)$ & $9.7(5.2-19.0)$ & $11.4(8.0-20.9)$ & 0.147 & - \\
\hline HOMA-IR & $3.11(2.14-4.94)$ & $2.28(1.16-4.73)$ & $2.73(2.07-4.80)$ & 0.087 & - \\
\hline
\end{tabular}

Data are reported as medians (interquartile range). $\mathrm{BMI}=$ body mass index; HOMA-IR $=$ homeostasis model assessment of insulin resistance; LDL-C $=$ low-density lipoprotein cholesterol; HDL-C $=$ high-density lipoprotein cholesterol. P value was compared among 3 genotypes by the kruskal-Wallis $\mathrm{H}$-test. ${ }^{\text {aP }}$ value between $\mathrm{CC}$ and CT genotype, adjusted for age, gender, and BMI by multinomial logistic regression. ${ }^{b} \mathrm{P}$ value between CC and TT genotype, adjusted for age, gender, and BMI by multinomial logistic regression.

This research discovered that rs371897784 in the PCSK1 gene was significantly different for median waist circumference between the wild-type (GG) and heterozygous variant genotype (GA). A patient with a heterozygous variant genotype had 1.249-fold greater risk $(\mathrm{P}=$ $0.027,95 \% \mathrm{CI}=1.081-1.444)$ of increased waist circumference than a patient with the wild-type genotype, after adjustment for age, gender, and BMI (Table 5).

\begin{tabular}{|c|c|c|c|c|}
\hline $\operatorname{rs} 371897784(\mathrm{G}>\mathrm{A})$ & $\mathrm{GG}(\mathrm{N}=72)$ & $\mathrm{GA}(\mathrm{N}=11)$ & $P$ value & Adjusted $\mathrm{P}$ value \\
\hline BMI & $29.2(24.7-35.2)$ & $32.4(26.1-42.7)$ & 0.301 & - \\
\hline Waist circumference $(\mathrm{cm})$ & $93.5(82.0-103.1)$ & $103.0(96.0-121.5)$ & 0.003 & $\begin{array}{c}0.027^{\mathrm{a}}(\mathrm{OR}=1.249 \\
95 \% \mathrm{CI}=1.081-1.444)\end{array}$ \\
\hline Total body fat percentage & $35.0(27.5-38.0)$ & $35.1(29.8-39.4)$ & 0.551 & - \\
\hline Cholesterol (mg/dL) & $196.5(174.3-221.3)$ & $196.0(167.0-220.0)$ & 0.914 & - \\
\hline Triglyceride (mg/dL) & $112.5(81.0-146.8)$ & $122.0(69.0-153.0)$ & 0.804 & - \\
\hline LDL calculated (mg/dL) & $118.5(96.7-146.8)$ & $122.0(108.0-146.0)$ & 0.712 & - \\
\hline HDL-CHOL (mg/dL) & $55.0(43.3-62.5)$ & $47.0(40.0-56.0)$ & 0.313 & - \\
\hline Glucose (mg/dL) & $91.0(85.3-105.8)$ & $91.0(88.0-97.0)$ & 0.638 & - \\
\hline $\mathrm{HbA1C}(\%)$ & $5.9(5.5-6.5)$ & $6.0(5.7-6.4)$ & 0.882 & - \\
\hline Insulin $(\mu \mathrm{U} / \mathrm{mL})$ & $11.0(6.6-21.2)$ & $12.9(8.3-25.1)$ & 0.347 & - \\
\hline HOMA-IR & $2.63(1.45-5.89)$ & $3.04(2.45-8.88)$ & 0.354 & - \\
\hline
\end{tabular}

Data are reported as medians (interquartile range). BMI $=$ body mass index; HOMA-IR $=$ homeostasis model assessment of insulin resistance; LDL-C $=$ low-density lipoprotein cholesterol; HDL-C $=$ high-density lipoprotein cholesterol. P value was compared between GG and GA genotype by the Mann-Whitney U-test. aP value adjusted for age, gender, and BMI by binary logistic regression, where GG genotype was the reference group.

Variant rs3811942 in the PCSK1 gene and variants rs1042571 and rs6713532 in the $P O M C$ gene displayed no significant association with anthropometric and biochemical parameters (data not shown). No association was observed between obesity and these six SNPs in the POMC and PCSK1 genes (data not shown) when the cut-off to categorize obesity for the Asian population at $\mathrm{BMI} \geq 25 \mathrm{~kg} / \mathrm{m}^{2}$ was used. 


\section{DISCUSSION}

This analysis did not find any association between any of the SNPs and obesity or BMI. This differed from our previous research, which investigated other SNPs of the PCSK1 gene (Kulanuwat et al., 2014), and differed from the other studies on Chinese and French Caucasian populations. In the Chinese populations studied by Chang et al. (2010), an association between obesity and rs155971 was found, but that association was not detected in the present study. This may be due to differences in ethnicity and different characteristics of the studied population; the present study investigated families. However, the results revealed that rs155971 was significantly associated with increased cholesterol and LDL-C levels when a patient had the homozygous variant genotype (TT) compared with the wild-type genotype (CC), after adjustment for age, gender, and BMI; the study of Chinese populations did not find any association (Chang et al., 2010). Again, the reasons for the disparity are probably differences in ethnicity and study population characteristics. The results indicate that rs 155971 is recessive and patients who showed an increase in cholesterol and LDL-C level must have had the $(\mathrm{C} \rightarrow \mathrm{T})$ variant at both alleles (homozygous variant). However, the mechanism or pathway by which the PCSK1 gene variant elevates cholesterol and LDL-C is unknown; therefore further study on this point is warranted.

Furthermore, the study in French Caucasian populations found an association between rs3762986 and rs3811942, and obesity. The variant rs3762986 increased the risk of obesity $(\mathrm{OR}=1.19,95 \% \mathrm{CI}=1.06-1.34)$, while $\mathrm{rs} 3811942$ protected against obesity $(\mathrm{OR}=0.82$, $95 \% \mathrm{CI}=0.76-0.99$ ) (Benzinou et al., 2008). In contrast, the present study did not find associations between these two SNPs and obesity. This inconsistency between the studies may be explained by the ethnic differences, differences in the characteristics of the studied population, which included families in our study, and the sample sizes involved. The present research revealed a significant difference between the median of glucose and $\mathrm{HbA} 1 \mathrm{C}$ levels among three genotypes of rs 3762986 . This is the first time that associations between glucose and HbA1C level and rs3762986 have been reported. However, these results were affected by age, gender, and BMI.

No previous study has analyzed the association between rs371897784 and obesity, and anthropometric and biochemical parameters; the present study revealed that rs 371897784 was significantly associated with waist circumference. After adjustment for age, gender, and BMI, a patient with the heterozygous variant genotype was at higher risk of increased waist circumference than a patient with the wild-type genotype.

Variants rs1042571 and rs6713532 in the POMC gene did not show any significant association with obesity, or anthropometric and biochemical parameters. The results of the present study differed from the family study in a white British population, which found an association between rs1042571 and WHR (Baker et al., 2005). Moreover, studies in the UK (Chen et al., 2005) and with Caucasian Americans (Wang et al., 2012) also found an association between rs1042571 and BMI. Baker et al. (2005) found no association between rs1042571 and BMI in a white British population, which agrees with the present study. Another SNP, rs6713532, has shown an association with WHR, visceral fat, and abdominal fat in a European population (Ternouth et al., 2011), but that association was not observed in the present study. Further research should be conducted using a larger sample size among the normal population and other Ethnic groups, to confirm an association.

In conclusion, this study found an association between rs155971 and cholesterol and 
LDL-C levels in the PCSK1 gene, a homozygous variant genotype indicating increased cholesterol and LDL-C levels. A significant association was found between rs3762986 in the PCSK1 gene and glucose and $\mathrm{HbA1C}$, but when adjusted for age, gender, and BMI, the relationship was not statistically significant. For anthropometric measurement, the results showed a significant relationship only for rs371897784 in the PCSK1 gene, with increased waist circumference. No relationship was observed between obesity and any of the six SNPs in the $P C S K 1$ and POMC genes.

\section{Conflicts of interest}

The authors declare no conflict of interest.

\section{ACKNOWLEDGMENTS}

The authors would like to thank all the staff at the following institutions for their help in the laboratory and for their friendship: the Department of Tropical Nutrition and Food Science, Faculty of Tropical Medicine; the Department of Pediatrics, Faculty of Medicine Siriraj Hospital; and the Department of Pediatrics, Faculty of Medicine Ramathibodi Hospital, Mahidol University. Many thanks to all volunteers for their blood samples. We also thank Mr. Paul Adams for proofreading the manuscript. Research supported by the Royal Golden Jubilee Ph.D. Program, the Thailand Research Fund/Mahidol University Joint Fund (grant \#PHD/0307/2551), the Research Fund of Mahidol University, and an NRU grant from the Center for Biopharmaceutical Development and Innovative Therapy, Mahidol University.

\section{REFERENCES}

Baker M, Gaukrodger N, Mayosi BM, Imrie H, et al. (2005). Association between common polymorphisms of the proopiomelanocortin gene and body fat distribution: a family study. Diabetes 54: 2492-2496.

Benzinou M, Creemers JW, Choquet H, Lobbens S, et al. (2008). Common nonsynonymous variants in PCSK1 confer risk of obesity. Nat. Genet. 40: 943-945.

Chang YC, Chiu YF, Shih KC, Lin MW, et al. (2010). Common PCSK1 haplotypes are associated with obesity in the Chinese population. Obesity 18: 1404-1409.

Chen Y, Snieder H, Wang X, Kaviya B, et al. (2005). Proopiomelanocortin gene variants are associated with serum leptin and body fat in a normal female population. Eur. J. Hum. Genet. 13: 772-780.

Choquet H and Meyre D (2010). Genomic insights into early-onset obesity. Genome Med. 2: 36.

Chung WK (2012). An overview of mongenic and syndromic obesities in humans. Pediatr. Blood Cancer 58: 122-128.

Farooqi IS, Volders K, Stanhope R, Heuschkel R, et al. (2007). Hyperphagia and early-onset obesity due to a novel homozygous missense mutation in prohormone convertase 1/3. J. Clin. Endocrinol. Metab. 92: 3369-3373.

Hager J, Dina C, Francke S, Dubois S, et al. (1998). A genome-wide scan for human obesity genes reveals a major susceptibility locus on chromosome 10. Nat. Genet. 20: 304-308.

Heni M, Haupt A, Schäfer SA, Ketterer C, et al. (2010). Association of obesity risk SNPs in PCSK1 with insulin sensitivity and proinsulin conversion. BMC Med. Genet. 11: 86.

Jackson RS, Creemers JW, Ohagi S, Raffin-Sanson ML, et al. (1997). Obesity and impaired prohormone processing associated with mutations in the human prohormone convertase 1 gene. Nat. Genet. 16: 303-306.

Jackson RS, Creemers JW, Farooqi IS, Raffin-Sanson ML, et al. (2003). Small-intestinal dysfunction accompanies the complex endocrinopathy of human proprotein convertase 1 deficiency. J. Clin. Invest. 112: 1550-1560.

Kagawa M, Uenishi K, Kuroiwa C, Mori M, et al. (2006). Is the BMI cut-off level for Japanese females for obesity set too high? A consideration from a body composition perspective. Asia Pac. J. Clin. Nutr. 15: 502-507.

Kilpeläinen TO, Bingham SA, Khaw KT, Wareham NJ, et al. (2009). Association of variants in the PCSK1 gene with obesity in the EPIC-Norfolk study. Hum. Mol. Genet. 18: 3496-3501. 
Kulanuwat S, Phonrat B, Tungtrongchitr A, Limwongse C, et al. (2014). Effects of PCSK1 genetic variants on obesity among Thai children and their family members: in relation to health risk, and biochemical and anthropometric parameters. Southeast Asian J. Trop. Med. Public Health 45: 214-225.

Loos RJ, Katzmarzyk PT, Rao DC, Rice T, et al. (2003). Genome-wide linkage scan for the metabolic syndrome in the HERITAGE Family Study. J. Clin. Endocrinol. Metab. 88: 5935-5943.

Pickett LA, Yourshaw M, Albornoz V, Chen Z, et al. (2013). Functional consequences of a novel variant of PCSK1. PLoS One 8: e55065.

Seidah NG, Mattei MG, Gaspar L, Benjannet S, et al. (1991). Chromosomal assignments of the genes for neuroendocrine convertase PC1 (NEC1) to human 5q15-21, neuroendocrine convertase PC2 (NEC2) to human 20p11.1-11.2, and furin (mouse 7[D1-E2] region). Genomics 11: 103-107.

Ternouth A, Brandys MK, van der Schouw YT, Hendriks J, et al. (2011). Association study of POMC variants with body composition measures and nutrient choice. Eur. J. Pharmacol. 660: 220-225.

Thaikruea L, Seetamanotch W and Seetamanotch S (2006). Appropriate cut-off level of BMI for screening in Thai adults. J. Med. Assoc. Thai. 89: 2123-2128.

Villalobos-Comparán M, Villamil-Ramírez H, Villarreal-Molina T, Larrieta-Carrasco E, et al. (2012). PCSK1 rs6232 is associated with childhood and adult class III obesity in the Mexican population. PLoS One 7: e39037.

Wang F, Gelernter J, Kranzler HR and Zhang H (2012). Identification of POMC exonic variants associated with substance dependence and body mass index. PLoS One 7: e45300.

Waterlow JC, Buzina R, Keller W, Lane JM, et al. (1977). The presentation and use of height and weight data for comparing nutritional status of groups of children under the age of 10 years. Bull. World Health Organ. 55: 489-498.

WHO/IASO/IOTF (2000). The Asia-Pacific perspective: redefining obesity and its treatment. Health Communications Australia, Melbourne. Available at [http://www.wpro.who.int/nutrition/documents/docs/Redefiningobesity. pdf?ua=1]. Accessed February 2015. 